\title{
QUALIDADE FISIOLÓGICA E TRATAMENTOS DE SEMENTES DE Cedrela fissilis PROCEDENTES DO SUL DO BRASIL ${ }^{1}$
}

\author{
Marília Lazarotto², Marlove Fátima Brião Muniz ${ }^{3}$, Rafael Beltrame ${ }^{4}$, AlvaroFigueredo dos Santos 5 , \\ Ricardo Mezzomo ${ }^{6}$, Graziela Piveta ${ }^{6}$ e Elena Blume ${ }^{3}$
}

\begin{abstract}
RESUMO - Os objetivos deste trabalho foram: avaliar a qualidade fisiológica de sementes de cedro (Cedrela fissilis), procedentes de localidades do sul do Brasil, através de testes de vigor e avaliar diferentes tratamentos nas sementes para controle de patógenos e para promoção da germinação da espécie. Para tanto, foram utilizadas seis amostras com procedências dos Estados do Rio Grande do Sul, Santa Catarina e Paraná, as quais foram submetidas à determinação de teor de água, teste de germinação e primeira contagem, envelhecimento acelerado (testando períodos de exposição às condições de envelhecimento), emergência em viveiro e tratamento de sementes. Os tratamentos utilizados para controle de patógenos foram: testemunha $\left(\mathrm{T}_{0}\right)$; físico com calor seco a $70^{\circ} \mathrm{C} \pm 3^{\circ} \mathrm{C}$ por 48 horas $\left(\mathrm{T}_{1}\right)$; extrato aquoso de alho (Allium sativum) $\left(\mathrm{T}_{2}\right)$; biológico à base de Trichoderma spp. - Agrotich Plus ${ }^{\circledR}\left(\mathrm{T}_{3}\right)$; e químico com fungicida protetor Captan $\left(\mathrm{T}_{4}\right)$. A germinação variou de 56 a 87\%; o período de $48 \mathrm{~h}$ sob temperatura de $41^{\circ} \mathrm{C}$ foi o mais eficiente para estratificar as amostras em níveis de vigor; a emergência variou de 51 a $88 \%$ e as variáveis de desempenho de plântulas analisadas conseguiram estratificar as amostras em níveis de vigor. Quanto ao tratamento de sementes, o calor seco e o tratamento à base de extrato de alho se mostram eficientes no controle de microrganismos em semente de cedro, sem prejuízos ao vigor destas.
\end{abstract}

Palavras-chave: Sementes florestais, Testes de vigor, Tratamentos alternativos.

\section{PHYSIOLOGICAL QUALITY SEEDS AND TREATMENTS OF Cedrela fissilis SEEDS FROM SOUTH OF BRAZIL}

\begin{abstract}
The objectives of this study were to evaluate the physiological quality of Cedrela fissilis seeds, from different origins, using different vigor tests and evaluating different seeds treatments for control of pathogens and to promote the germination of the species. Therefore, six samples from different places in states of Rio Grande do Sul, Santa Catarina and Paraná were used, which were subjected to determination of water content, germination and first count of germination, accelerated aging (testing different periods), emergence, with assessments seedlings and seed treatment. The treatments were the following: control $\left(T_{0}\right)$; physical treatment with dry heat at $70^{\circ} \mathrm{C} \pm 3^{\circ} \mathrm{C}$ for 48 hours $\left(T_{1}\right)$; aqueous extract of Allium sativum $\left(T_{2}\right)$; biological with product based on Trichoderma spp. - Agrotich Plus ${ }^{\circledR}\left(T_{3}\right)$; and chemic with fungicide Captan $\left(T_{4}\right)$. Germination ranged 56-87\%, the period of 48 hours at a temperature of $41^{\circ} \mathrm{C}$ has been more efficient to stratify the samples at levels of vigor; emergence ranged 51-88\% and the performance of seedlings variables were able to stratify the samples analyzed at levels of vigor. Regarding seed treatments, dry heat and treatment based on extracts of A. sativum are effective in controlling micro-organisms in $\boldsymbol{C}$. fissilis seeds, without damage to the vigor of them.
\end{abstract}

Keywords: Forest seeds, Vigor tests, Alternative treatments.

\footnotetext{
${ }^{1}$ Recebido em 11.08.2010 aceito para publicação em 05.04.2013.

${ }^{2}$ Universidade Federal de Pelotas, UFPEL, Brasil. E-mail:<lilalazarotto@ yahoo.com.br>.

${ }^{3}$ Departamento de Defesa Fitossanitária, Universidade Federal de Santa Maria, UFSM, Brasil. E-mail:<marlovemuniz@ yahoo.com.br $>$ e <elenablu@gmail.com>.

${ }^{4}$ Universidade Federal de Pelotas, UFPEL, Brasil. E-mail:<beltrame.rafael@yahoo.com.br>.

${ }^{5}$ Empresa Brasileira de Pesquisa Agropecuária, Centro Nacional de Pesquisa de Florestas, Laboratório de Fitopatologia. E-mail:<alvaro.santos@embrapa.br>.

${ }^{6}$ Programa de Pós-Graduação em Engenharia Florestal na Universidade Federal de Santa Maria, UFSM, Brasil. E-mail:<mezzomoricardo@hotmail.com>e<grazielapiveta@yahoo.com.br>.
} 


\section{INTRODUÇÃO}

O cedro (Cedrela fissilis Vell.), pertencente à família Meliaceae, é uma árvore de 20 a 35 m de altura e tronco de 60 a $90 \mathrm{~cm}$ de diâmetro que ocorre desde o Rio Grande do Sul até Minas Gerais, nas Florestas Semidecídua e Pluvial Atlântica (LORENZI, 1992). A alta qualidade e o alto valor comercial da madeira de $C$. fissilis a tornam alvo do extrativismo e da exploração indiscriminada, mesmo nos dias atuais, acarretando derrubadas desproporcionais nas formações vegetais onde ocorre naturalmente (RUIZ FILHO et al., 2004).

Conforme Guedes et al. (2009a), as sementes constituem a via de propagação mais empregada na implantação de florestas, devido ao fato de ser um meio rápido e geralmente não dispendioso, sendo de fundamental interesse o estudo de vários fatores que interferem na propagação, principalmente a germinação e vigor, que influenciam de forma direta na dispersão das espécies.

Os testes de vigor têm se constituído em ferramentas de uso cada vez mais rotineiro para determinação da qualidade fisiológica pela indústria de sementes, sendo importantes para avaliar diferenças significativas na qualidade fisiológica de lotes com germinação semelhante, complementando as informações fornecidas pelo teste de germinação (MARCOS FILHO, 1999). Além do conhecimento da qualidade fisiológica das sementes que serão utilizadas para a propagação de uma espécie, é imprescindível que estas sejam sadias, ou seja, com qualidade sanitária superior. Para que essa qualidade seja alcançada, muitas vezes podem se empregar alguns tratamentos para a redução de microrganismos associados a essas sementes, como tratamento químico, biológico, físico ou a utilização de extratos vegetais com propriedades antifúngicas (LAZAROTTO, 2010).

Diante do exposto, este trabalho teve como objetivos: avaliar a qualidade fisiológica de sementes de cedro, procedentes de diferentes localidades, através de testes de vigor, testar diferentes períodos de exposição ao teste de envelhecimento acelerado e avaliar tratamentos nas sementes de cedro para controle de patógenos.

\section{MATERIAL E MÉTODOS}

\subsection{Origem das sementes e local dos experimentos}

As sementes de cedro foram obtidas através de três bancos de sementes: Bolsa de Sementes do Viveiro Florestal da UFSM; Fundação Estadual de Pesquisa
Agropecuária Fepagro Florestas - Estação Experimental Boca do Monte; e Banco de Sementes da Embrapa Florestas localizado em Colombo, PR, totalizando seis amostras de diferentes procedências, sendo elas: SM - Santa Maria, RS; SMO - São Miguel do Oeste, SC; IRATI - Irati, SC; CAZUL -Cerro Azul, PR; LAPA Contenda da Lapa, PR; e LARGO - Campo largo, PR, coletadas entre os meses de junho e julho de 2008 . Todos os experimentos realizados com avaliação de plântulas foram conduzidos em casa de vegetação, com irrigação diária, sem controle de temperatura e umidade. As sementes foram coletadas e processadas pelos bancos de sementes de onde foram adquiridas e armazenadas em câmara fria (temperaturas entre 5 e $10{ }^{\circ} \mathrm{C}$ e baixa umidade relativa) até que fossem enviadas para a realização deste estudo.

\subsection{Determinação do teor de água, germinação e primeira contagem}

Para determinação do teor de água das sementes de cedro, foram utilizadas 80 sementes, divididas em quatro repetições de 20. Estas foram colocadas em estufa na temperatura de $105 \pm 3{ }^{\circ} \mathrm{C}$, durante $24 \mathrm{~h}$ (BRASIL, 2009).

Para germinação, o substrato rolo de papel foi o escolhido, segundo recomendações de Wielewicki et al. (2006). Foram utilizadas 200 sementes, divididas em quatro repetições de 50, em rolo de papel, umedecido com água destilada esterilizada (2,5 vezes o peso do papel seco). As sementes foram desinfetadas em álcool 70\% (30 s), hipoclorito de sódio $1 \%$ (2 min) e, após, lavadas em água destilada esterilizada. A incubação foi realizada em câmara com temperatura controlada de $25^{\circ} \mathrm{C}$ e fotoperíodo de $12 \mathrm{~h}$. A avaliação do vigor, através da primeira contagem de germinação, realizou-se aos sete dias, a contar da instalação do teste; e a germinação, avaliada aos 14 dias. A primeira contagem foi somente de plântulas normais e, a segunda, de plântulas normais, anormais, sementes duras e mortas.

\subsection{Envelhecimento acelerado}

As sementes de cedro foram submetidas ao envelhecimento acelerado da seguinte forma: utilizaram-se caixas plásticas do tipo "gerbox", que funcionam como minicâmaras (compartimento individual). As 100 sementes utilizadas para cada tratamento foram distribuídas uniformemente, de maneira a formar uma camada simples 
sobre a superfície de tela metálica suspensa no interior da caixa plástica (compartimento interno), as quais continham $40 \mathrm{ml}$ de água destilada, obtendo-se, aproximadamente, $100 \%$ de umidade relativa do ar e na temperatura de $41{ }^{\circ} \mathrm{C}$. Os tratamentos foram compostos por diferentes tempos de exposição às condições de estresse: $0\left(\mathrm{~T}_{0}\right), 24\left(\mathrm{~T}_{1}\right), 48\left(\mathrm{~T}_{2}\right), 72\left(\mathrm{~T}_{3}\right)$ e $96 \mathrm{~h}\left(\mathrm{~T}_{4}\right)$, a fim de se estabelecer o período necessário para diferenciação das amostras com diferentes níveis de vigor. Após esses períodos, as sementes foram, então, desinfestadas e colocadas para germinar em rolo de papel, como já apresentado no teste de germinação (item 2.2). Realizou-se, aos 14 dias, a avaliação de plântulas normais, expressa em porcentagem.

\subsection{Emergência em viveiro}

Foram utilizadas 100 sementes de cada procedência, divididas em quatro repetições de 25 , colocadas em bandejas de isopor com vermiculita fina. As avaliações foram: a) emergência: aos 14 e 35 dias, computandose o número de plântulas emergidas, sendo os resultados expressos em porcentagem. Na última contagem de emergência (35 dias), realizaram-se as avaliações seguintes; b) comprimento de mudas: mediramse 10 mudas por repetição, com o auxílio de régua graduada; após, fez-se a média, cujos resultados foram expressos em cm; c) massa fresca de mudas: todas as mudas de cada repetição foram pesadas em balança analítica de precisão de 0,001 g. Os resultados médios foram expressos em g; d) massa seca de mudas: as mudas utilizadas na determinação da massa fresca foram acondicionadas em sacos de papel e colocadas em estufa a $80^{\circ} \mathrm{C} \pm 3^{\circ} \mathrm{C}$, por $24 \mathrm{~h}$, para posterior pesagem (CHEROBINI et al., 2008). Os resultados médios foram expressos em $\mathrm{g}$.

\subsection{Tratamentos de sementes}

Três amostras de sementes de cedro foram utilizadas: Santa Maria, RS (SM), Cerro Azul, PR (CAZUL) e Irati, SC (IRATI), a fim de abranger procedências com diferentes resultados nos testes de vigor. Os tratamentos utilizados foram: testemunha $\left(\mathrm{T}_{0}\right)$; tratamento físico $\left(\mathrm{T}_{1}\right)$, em que as sementes foram submetidas ao calor seco em estufa, a $70{ }^{\circ} \mathrm{C} \pm 3{ }^{\circ} \mathrm{C}$ por $48 \mathrm{~h}$; tratamento com extrato aquoso de alho (Allium sativum) $\left(\mathrm{T}_{2}\right)$, triturando-se $10 \mathrm{~g}$ de bulbilhos de alho para $100 \mathrm{ml}$ de água (relação p/v). Essa mistura foi coada em gaze de algodão e, em seguida, as sementes foram imersas no extrato resultante por
$15 \mathrm{~min}$; tratamento biológico $\left(\mathrm{T}_{3}\right)$, com produto comercial à base de Trichoderma spp., na formulação em pó Agrotich Plus ${ }^{\circledR}$. Foi utilizada uma dose arbitrária do produto biológico de 0,25 g/100 g de sementes; e tratamento químico $\left(\mathrm{T}_{4}\right)$, com fungicida protetor Captan, produto comercial Captan 500 pó molhável, na dose recomendada para a cultura de soja $(0,18 \mathrm{~g} / 100 \mathrm{~g}$ de sementes). Nos tratamentos $\mathrm{T}_{3}$ e $\mathrm{T}_{4}$, os produtos e as sementes foram colocados em frascos de vidro de 500 $\mathrm{ml}$, aos quais se adicionou água destilada esterilizada ( $5 \%$ do peso total das sementes) e, posteriormente, foram agitados manualmente por $5 \mathrm{~min}$. As sementes tratadas foram submetidas a três avaliações: a) teste de germinação, como descrito no item 2.2 ; b) teste de sanidade em papel-filtro, com 100 sementes de cada procedência, divididas em quatro repetições de 25 , colocadas em caixas plásticas desinfestadas com hipoclorito de sódio $1 \%$, com duas folhas de papelfiltro esterilizado e umedecido com água estéril. A identificação dos fungos ocorreu após sete dias da instalação; e c) teste de emergência, avaliação das variáveis: emergência aos 35 dias, comprimento, massa fresca e massa seca de mudas, como descrito na emergência em viveiro (item 2.4).

\subsection{Procedimento estatístico}

O delineamento experimental utilizado foi completamente casualizado, com quatro repetições de cada teste. Para a análise de variância, os dados foram transformados em arcosseno $\sqrt{\mathrm{x}} / 100$. A comparação das médias foi feita pelo teste de Tukey a $5 \%$ de probabilidade. Para o teste de envelhecimento acelerado e experimento de tratamentos, o arranjo foi bifatorial, composto por 6 x 5 (procedências x tempos de exposição ao envelhecimento) e $3 \times 5$ (procedências x tratamentos), respectivamente. Para os demais testes, um único fator foi comparado.

\section{RESULTADOS}

\subsection{Avaliação do potencial fisiológico das sementes}

Os valores de teor de água variaram de 13,3 a 20,8\% entre as amostras (Tabela 1). Neste trabalho, a amostra com maior teor de água (SM) apresentou a maior porcentagem de sementes germinadas na primeira contagem, bem como alta germinação, representada pelas plântulas normais, não diferindo estatisticamente da melhor amostra, o que sugere que a alta umidade não prejudicou a viabilidade das sementes. A procedência

Revista Árvore, Viçosa-MG, v.37, n.2, p.201-210, 2013 
de Santa Maria (SM) apresentou maior porcentagem de sementes germinadas na primeira contagem e, para plântulas normais, as quais representaram a germinação, Cerro Largo (LARGO) foi a superior, e SM e Cerro Azul (CAZUL) também não diferiram desta (Tabela 1). A porcentagem de plântulas anormais foi superior na amostra de Irati, e a de sementes duras e mortas, na de São Miguel do Oeste (SMO). Essas duas últimas procedências também foram inferiores quanto às variáveis primeira contagem de germinação e plântulas normais, representando as duas amostras de mais baixo vigor nesses testes.

Quanto ao teste de envelhecimento acelerado (Tabela 1), verificou-se interação significativa entre procedências e períodos de envelhecimento dentro de cada procedência. Observa-se, nas linhas referentes ao envelhecimento, que todas as amostras tiveram sua germinação significativamente reduzida, após breves períodos de envelhecimento ( 24 e 48 h). Algumas das amostras permaneceram com a germinação superior em relação às demais, após o envelhecimento, sendo possível identificar os lotes de maior e menor vigor. No período de $24 \mathrm{~h}$ de envelhecimento, apenas a amostra SMO demonstrou vigor extremamente baixo, por ter sua germinação comprometida já nesse primeiro tratamento. O período de 48 h na temperatura de 41
${ }^{\circ} \mathrm{C}$ já foi eficiente para estratificar as amostras em níveis de vigor, ressaltando-se que SM e LARGO obtiveram as mais altas porcentagens de germinação após o envelhecimento, indicando qualidade fisiológica superior.

As variáveis que avaliaram o vigor das mudas produzidas em viveiro também foram eficientes em diferenciar procedências mais vigorosas daquelas com menor vigor (Tabela 2), como o ocorrido no envelhecimento acelerado (Tabela 1). As sementes procedentes de Santa Maria, SM, obtiveram maior emergência ao final de 35 dias, seguida das procedências de Cerro Azul - CAZUL e Campo Largo - LARGO, em que as duas últimas haviam apresentado maior emergência aos 14 dias. Com relação às variáveis comprimento de mudas, massa fresca e massa seca, CAZULe Contenda da Lapa - LAPA obtiveram as maiores médias, demonstrando que, apesar de não apresentarem emergência superior, suas mudas foram mais vigorosas em relação às variáveis analisadas.

\subsection{Tratamento de sementes}

Na Figura 1, verificam-se as interações significativas entre os diferentes tratamentos e as três procedências utilizadas. O tratamento físico aumentou a porcentagem

Tabela 1 - Resultados médios (\%) do teor de água, do teste de germinação e do envelhecimento acelerado para seis procedências de sementes de cedro.

Table 1 - Means (\%) of water content, germination test and accelerated aging for six provenances of $\boldsymbol{C}$. fissilis seeds.

\begin{tabular}{|c|c|c|c|c|c|c|}
\hline \multirow{2}{*}{ Procedências } & \multicolumn{6}{|c|}{ Variáveis analisadas (\%) } \\
\hline & $\mathrm{TU}$ & PCG & $\mathrm{PN}$ & PA & $\mathrm{SD}$ & SM \\
\hline SM & $20,8 \mathrm{~A} *$ & $64 \mathrm{~A}$ & $84 \mathrm{AB}$ & $7 \mathrm{C}$ & $3 \mathrm{C}$ & $6 \mathrm{C}$ \\
\hline SMO & 19,9 A & $22 \mathrm{D}$ & $56 \mathrm{D}$ & $6 \mathrm{D}$ & $12 \mathrm{~A}$ & $26 \mathrm{~A}$ \\
\hline IRATI & $18,7 \mathrm{~A}$ & $25 \mathrm{D}$ & $67 \mathrm{C}$ & $16 \mathrm{~A}$ & $5 \mathrm{BC}$ & $12 \mathrm{~B}$ \\
\hline CAZUL & $19,5 \mathrm{~A}$ & $46 \mathrm{C}$ & $84 \mathrm{AB}$ & $11 \mathrm{~B}$ & $3 \mathrm{C}$ & $2 \mathrm{D}$ \\
\hline LAPA & $13,3 \mathrm{~B}$ & $43 \mathrm{C}$ & $80 \mathrm{~B}$ & $7 \mathrm{C}$ & $6 \mathrm{~B}$ & $7 \mathrm{C}$ \\
\hline LARGO & $13,5 \mathrm{~B}$ & 59 B & $87 \mathrm{~A}$ & $9 \mathrm{BC}$ & $1 \mathrm{D}$ & $3 \mathrm{D}$ \\
\hline $\mathrm{CV}(\%)$ & 6,9 & 8,6 & 7,0 & 13,9 & 13,9 & 14,9 \\
\hline \multirow{2}{*}{ Procedências } & \multicolumn{6}{|c|}{ Períodos de envelhecimento (horas) } \\
\hline & 0 & 24 & 48 & 72 & & 96 \\
\hline SM & $80 \mathrm{Aa}^{*}$ & $68 \mathrm{Bb}$ & $64 \mathrm{Ab}$ & $58 \mathrm{ABb}$ & & $53 \mathrm{Ab}$ \\
\hline $\mathrm{SMO}$ & $56 \mathrm{Ca}$ & $1 \mathrm{Cb}$ & $0 \mathrm{Cb}$ & $0 \mathrm{Db}$ & & $0 \mathrm{Cb}$ \\
\hline IRATI & $77 \mathrm{BCa}$ & $70 \mathrm{ABa}$ & $43 \mathrm{Bb}$ & $29 \mathrm{Cc}$ & & $0 \mathrm{Cd}$ \\
\hline CAZUL & $84 \mathrm{Aa}$ & $66 \mathrm{Bb}$ & $50 \mathrm{ABc}$ & $42 \mathrm{BCc}$ & & $16 \mathrm{Bd}$ \\
\hline LAPA & $80 \mathrm{Aa}$ & $62 \mathrm{Bb}$ & $56 \mathrm{ABbc}$ & $54 \mathrm{ABbc}$ & & $45 \mathrm{Ac}$ \\
\hline LARGO & 84 Aa & $78 \mathrm{Aa}$ & $64 \mathrm{Ab}$ & $62 \mathrm{Ab}$ & & $52 \mathrm{Ab}$ \\
\hline
\end{tabular}

* Médias seguidas por mesma letra maiúscula na coluna e minúscula na linha não diferem entre si pelo teste de Tukey ao nível de 5\% de probabilidade. Em que: SM: Santa Maria-RS; SMO: São Miguel do Oeste-SC; IRATI: Irati-SC; CAZUL: Cerro Azul-PR; LAPA: Contenda da Lapa-PR; LARGO: Campo Largo-PR; TU: Teor de Água; PCG: Primeira Contagem de Germinação; PN: Plântulas Normais; PA: Plântulas Anormais; SD: Sementes Duras; SM: Sementes Mortas; CV (\%) para a variável plântulas normais do envelhecimento acelerado: $10,3 \%$.

Revista Árvore, Viçosa-MG, v.37, n.2, p.201-210, 2013 
Tabela 2 - Avaliação da qualidade de mudas de cedro, obtidas de sementes coletadas em seis procedências, através das variáveis: emergência aos 14 dias (E14), emergência aos 35 dias (E35), comprimento de mudas (CP), massa fresca (MF) e massa seca (MS).

Table 2 - Quality of $\boldsymbol{C}$. fissilis seedlings obtained from seeds collected from six origins, through the variables: emergence at 14 days (E14), emergence to 35 days (E35), seedling length (CM), fresh weight (MF) and dry weight (MS).

\begin{tabular}{lccccc}
\hline \multirow{2}{*}{ Procedências } & \multicolumn{5}{c}{ Variáveis } \\
\cline { 2 - 6 } & E14 $(\%)$ & E35 $(\%)$ & CP $(\mathrm{cm} /$ muda $)$ & MF $(\mathrm{g} /$ muda $)$ & MS $(\mathrm{g} /$ muda $)$ \\
\hline SM & $4 \mathrm{~b}^{*}$ & $88 \mathrm{a}$ & $8,14 \mathrm{c}$ & $0,205 \mathrm{~b}$ & $0,035 \mathrm{c}$ \\
SMO & $9 \mathrm{~b}$ & $23 \mathrm{~d}$ & $10,02 \mathrm{ab}$ & $0,295 \mathrm{~b}$ & $0,048 \mathrm{bc}$ \\
IRATI & $11 \mathrm{~b}$ & $62 \mathrm{bc}$ & $9,39 \mathrm{bc}$ & $0,268 \mathrm{~b}$ & $0,046 \mathrm{bc}$ \\
CAZUL & $33 \mathrm{a}$ & $81 \mathrm{ab}$ & $11,53 \mathrm{a}$ & $0,390 \mathrm{a}$ & $0,077 \mathrm{a}$ \\
LAPA & $12 \mathrm{~b}$ & $51 \mathrm{c}$ & $11,42 \mathrm{a}$ & $0,455 \mathrm{a}$ & $0,082 \mathrm{a}$ \\
LARGO & $40 \mathrm{a}$ & $76 \mathrm{ab}$ & $10,10 \mathrm{ab}$ & $0,300 \mathrm{~b}$ & $0,051 \mathrm{~b}$ \\
CV $(\%)$ & 28,4 & 12,0 & 7,8 & 15,1 & 10,4 \\
\hline
\end{tabular}

* Médias seguidas por mesma letra na coluna não diferem entre si pelo teste de Tukey ao nível de 5\% de probabilidade. Em que: SM: Santa MariaRS; SMO: São Miguel do Oeste-SC; IRATI: Irati-SC; CAZUL: Cerro Azul-PR; LAPA: Contenda da Lapa-PR; LARGO: Campo Largo-PR.

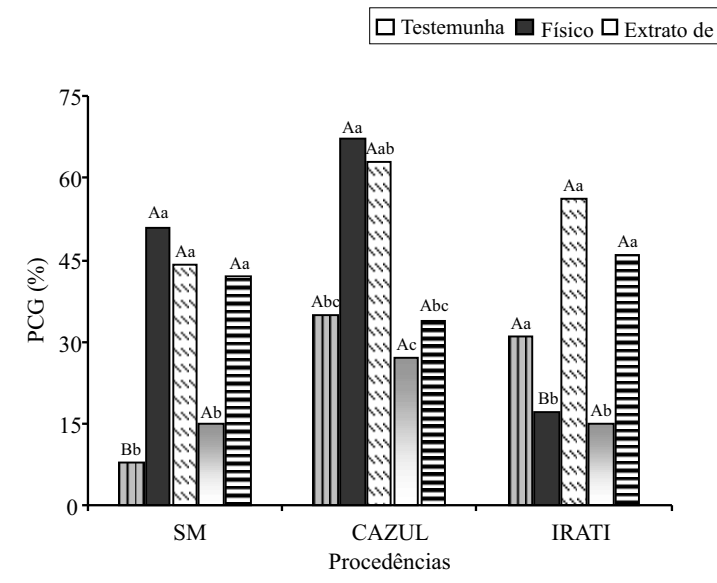

$\square$ Biológico $\square$ Químico

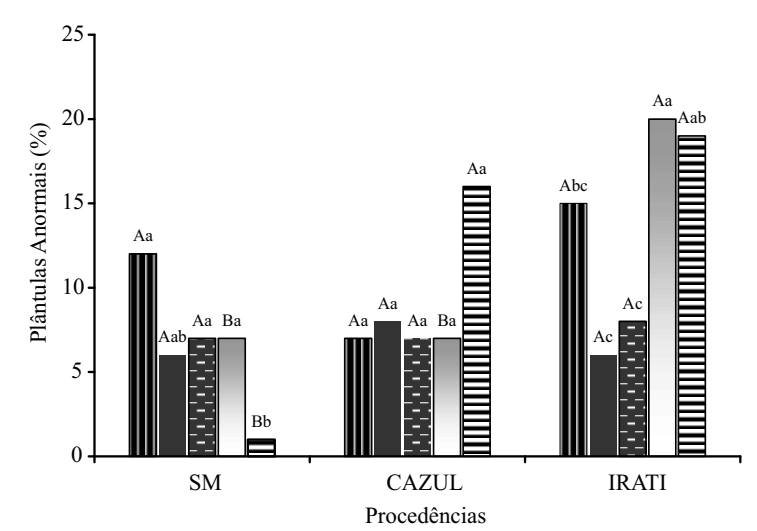

Figura 1 - Gráfico da primeira contagem de germinação (A); plântulas normais (B) e plântulas anormais (C) de três procedências de sementes de cedro após diferentes tratamentos. As letras maiúsculas representam o teste de Tukey a 5\% entre procedências e as minúsculas entre tratamentos para a mesma procedência.

Figure 1 - Graph of the first count of germination (A), normal seedlings (B) and abnormal seedlings $(C)$ of three origins of $\boldsymbol{C}$. fissilis seeds after different treatments. The capital letters represent the Tukey test at $5 \%$ between origins and treatments for the tiny between the same origin. 
de plântulas normais na primeira contagem de germinação (PCG), nas procedências SM e CAZUL; no entanto, para IRATI houve redução dessa variável. O tratamento com extrato de alho foi tão eficiente quanto o tratamento físico e o químico em SM, ao físico em CAZUL, e estatisticamente idêntico ao químico em IRATI.

Na germinação, representada pelas plântulas normais, o extrato de alho foi eficiente nas três procedências testadas. $\mathrm{Na}$ amostra $\mathrm{SM}$, o tratamento físico obteve a menor porcentagem de plântulas normais (Figura 1). Já para IRATI os tratamentos com extrato de alho e químico foram superiores ao físico e biológico, porém não diferindo da testemunha. $\mathrm{O}$ extrato de alho poderia ser adotado para tratamento de sementes de cedro, já que aumenta a germinação de lotes com viabilidade inferior e não altera a germinação de lotes com qualidade elevada. Com relação às plântulas anormais, diferentes resultados puderam ser observados em cada procedência, sendo o tratamento químico aquele que mais reduziu essa variável na amostra SM, bem como o tratamento físico e o extrato de alho, na amostra IRATI. Para as demais variáveis, sementes duras e mortas, a interação não foi significativa, por isso não são apresentadas na Figura 1. Dessa forma, verificou-se que cada tratamento obteve determinado efeito, dependendo da procedência de sementes que estava sendo utilizada, entretanto, para as variáveis primeira contagem de germinação e plântulas normais, o extrato de alho foi eficiente nas três precedências.

Na Figura 2, observa-se que a emergência aos 35 dias (E35) foi inferior no tratamento químico na procedência SM, assim como o tratamento físico, já nas procedências CAZULe IRATI o tratamento biológico à base de Trichoderma spp. foi o que apresentou médias inferiores nessa variável. O comprimento de mudas foi estatisticamente igual entre os tratamentos na procedência SM; já em CAZUL o extrato de alho se mostrou superior, o mesmo ocorrendo em IRATI, porém, nesta última, a testemunha e o tratamento químico com Captan foram estatisticamente iguais. As interações foram não significativas nas variáveis massa fresca e massa seca, por isso não foram apresentados na Figura 2. Novamente, o comportamento de cada tratamento entre as diferentes procedências foi variado, entretanto o extrato de alho foi o mais favorável no tratamento de sementes das variáveis emergência e comprimento de mudas.

Revista Árvore, Viçosa-MG, v.37, n.2, p.201-210, 2013
Pode-se constatar que, de maneira geral, os tratamentos físico e com extrato de alho foram os que apresentaram melhores resultados na maioria das variáveis de vigor de sementes e crescimento de mudas (Figuras 1 e 2). Esse fato demonstra a capacidade de os tratamentos promover o crescimento, dando origem a mudas mais vigorosas que apresentaram, consequentemente, melhor qualidade.

Os resultados do teste de sanidade em sementes de cedro, após diferentes tratamentos, estão apresentados na Tabela 3. Observa-se que o fungo Aspergillus sp. ocorreu, em maiores incidências e nas três procedências, no tratamento físico com calor seco $\left(70^{\circ} \mathrm{C}\right.$ em estufa por $48 \mathrm{~h}$ ); o fungo Penicillium $\mathrm{sp}$. ocorreu em maior incidência no tratamento biológico somente para SM a testemunha obteve maior incidência desse fungo; o fungo Phomopsis sp. foi erradicado, em todas as procedências, pelo tratamento físico e, pelo extrato de alho, na procedência SM.

O tratamento físico também conseguiu erradicar o fungo Rhizoctonia sp. nas três procedências, o biológico erradicou em CAZUL; IRATI, já o químico só foi eficiente para esse fungo em IRATI. Considerando que fungos do gênero Rhizoctonia podem se tornar patogênicos em plântulas, tratamentos que eliminam esse patógeno das sementes são imprescindíveis para a produção de sementes sadias. Com relação à porcentagem de sementes sadias (isentas de patógenos), observou-se claramente que o tratamento com extrato de alho obteve as maiores médias. Depois desse, o tratamento químico foi o que obteve resultados consideráveis de sementes sadias.

Verificou-se que o tratamento físico foi o mais eficiente na eliminação completa dos principais patógenos, como Rhizoctonia sp. e Phomopsis sp. (Tabela 3), que poderiam se tornar patogênicos a plântulas de cedro, porém, nesse mesmo tratamento, houve alta incidência de Aspergillus sp., que poderia diminuir o porcentual de germinação total de sementes. Isso ocorreu, pois o tratamento físico com calor seco proporcionou uma completa esterilização das sementes, criando um "vácuo biológico" que pode ser preenchido tanto por organismos saprófitas, como Aspergillus sp., quanto por patógenos que podem colonizar rapidamente o substrato, pela ausência de organismos supressores com potencial controle biológico. O tratamento com extrato de alho não chegou a erradicar 


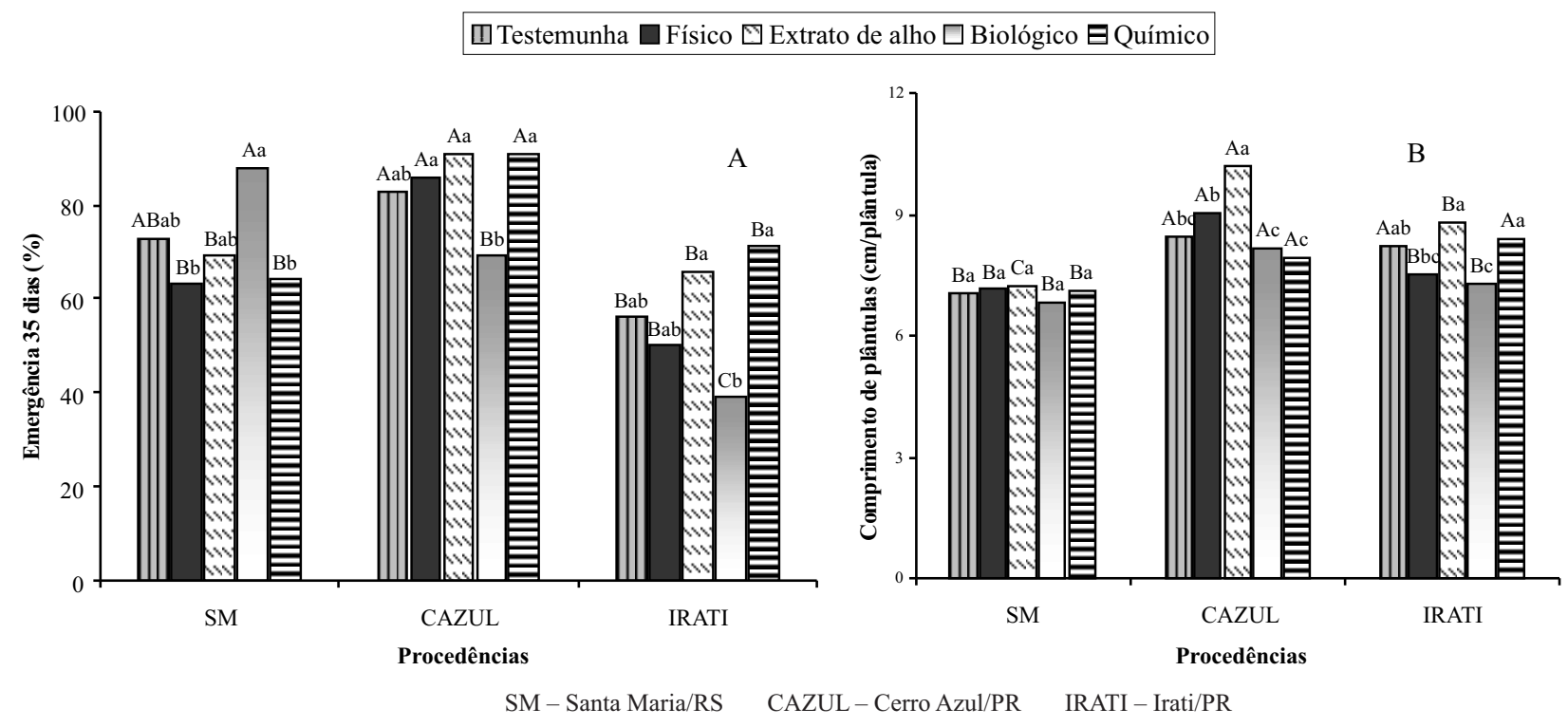

Figura 2 - Gráfico da emergência aos 35 dias (A) e comprimento de mudas (B) de três procedências de sementes de cedro após diferentes tratamentos. As letras maiúsculas representam o teste de Tukey a 5\% entre procedências e as minúsculas entre tratamentos para a mesma procedência.

Figure 2 - Graph of emergency to 35 days (A) and length of seedlings $(B)$ of three origins of $\boldsymbol{C}$. fissilis seeds after different treatments. The capital letters represent the Tukey test at $5 \%$ between origins and treatments for the tiny between the same origin.

Tabela 3 - Incidência de fungos (\%) associados à sementes de cedro de três procedências após diferentes tratamentos das sementes.

Table 3 - Fungal incidence (\%) associated with $\boldsymbol{C}$. fissilis seeds of three origins after different treatments of the seeds.

\begin{tabular}{lcccccc}
\hline \multirow{2}{*}{ Variável } & \multirow{2}{*}{ Procedências } & \multicolumn{4}{c}{ Tratamentos } \\
\cline { 3 - 7 } & & Testemunha & Físico & Extrato & Biológico & Químico \\
\hline & CAZUL & $40 \mathrm{ABb}$ & $74 \mathrm{Aa}$ & $1 \mathrm{Ad}$ & $17 \mathrm{Bc}$ & $0 \mathrm{Ad}$ \\
Aspergillus spp.CV (\%): 21,0 & IRATI & $47 \mathrm{Aab}$ & $58 \mathrm{Aa}$ & $0 \mathrm{Ac}$ & $3 \mathrm{Cc}$ & $0 \mathrm{Ac}$ \\
& SM & $28 \mathrm{Aa}$ & $8 \mathrm{Bbc}$ & $4 \mathrm{Bcd}$ & $15 \mathrm{Aab}$ & $0 \mathrm{Bd}$ \\
Penicillium spp.CV (\%): 28,2 & CAZUL & $12 \mathrm{Ba}$ & $7 \mathrm{Ba}$ & $15 \mathrm{Aa}$ & $12 \mathrm{Aa}$ & $8 \mathrm{Aa}$ \\
& IRATI & $4 \mathrm{Bb}$ & $20 \mathrm{Aa}$ & $5 \mathrm{Bb}$ & $19 \mathrm{Aa}$ & $7 \mathrm{Aab}$ \\
& SM & $21 \mathrm{Bb}$ & $0 \mathrm{Ac}$ & $0 \mathrm{Cc}$ & $23 \mathrm{Bab}$ & $34 \mathrm{Aa}$ \\
Phomopsisspp.CV $(\%): 16,1$ & CAZUL & $31 \mathrm{Aab}$ & $0 \mathrm{Ac}$ & $16 \mathrm{Ab}$ & $52 \mathrm{Aa}$ & $28 \mathrm{ABab}$ \\
& IRATI & $15 \mathrm{Bab}$ & $0 \mathrm{Ad}$ & $7 \mathrm{Bbc}$ & $15 \mathrm{Bab}$ & $22 \mathrm{Ba}$ \\
& SM & $6 \mathrm{Bab}$ & $0 \mathrm{Ac}$ & $4 \mathrm{Aab}$ & $1 \mathrm{Abc}$ & $8 \mathrm{Aa}$ \\
Rhizoctoniaspp.CV $(\%): 30,7$ & CAZUL & $15 \mathrm{Aa}$ & $0 \mathrm{Ab}$ & $3 \mathrm{Ab}$ & $0 \mathrm{Ab}$ & $9 \mathrm{Aa}$ \\
& IRATI & $6 \mathrm{Ba}$ & $0 \mathrm{Ab}$ & $6 \mathrm{Aa}$ & $0 \mathrm{Ab}$ & $0 \mathrm{Bb}$ \\
& $\mathrm{SM}$ & $0 \mathrm{Ad}$ & $12 \mathrm{Ac}$ & $82 \mathrm{Aa}$ & $0 \mathrm{Bd}$ & $38 \mathrm{Ab}$ \\
Sementes sadiasCV $(\%): 20,5$ & CAZUL & $0 \mathrm{Ac}$ & $0 \mathrm{Bc}$ & $47 \mathrm{Ba}$ & $13 \mathrm{Ab}$ & $31 \mathrm{Aa}$ \\
& IRATI & $0 \mathrm{Ad}$ & $11 \mathrm{Ac}$ & $82 \mathrm{Aa}$ & $0 \mathrm{Bd}$ & $42 \mathrm{Ab}$ \\
\hline
\end{tabular}

* Médias seguidas por mesma letra maiúscula na coluna e minúscula na linha não diferem entre si pelo teste de Tukey ao nível de $5 \%$ de probabilidade. Em que: SM: Santa Maria-RS; CAZUL: Cerro Azul-PR; IRATI: Irati-SC; Físico: estufa a $70^{\circ} \mathrm{C}$ por 48 h; Extrato: extrato de alho; Biológico: Agrotrich Plus ${ }^{\circledR}$ (250 g/100 kg de sementes); Químico: Captan (180 g/ 100 kg sementes). 
tais patógenos, no entanto conseguiu manter a maior parte dos fungos em baixas incidências, além de obter a maioria das sementes sadias e, consequentemente, médias altas nas variáveis emergência de plântulas (Figura 2) e germinação (Figura 1).

\section{DISCUSSÃO}

Com relação ao teor de água das sementes, que ficaram entre 13,3 e 20,8\%, Martins e Lago (2008) verificaram que teores de água superiores a $12,4 \%$ desfavorecem a conservação das sementes de cedro, provocando diminuição significativa da viabilidade destas após longos períodos de armazenamento. Essa grande diferença nos graus de umidade entre as procedências implica variações na qualidade e vigor das sementes, que são detectados, principalmente, em testes de envelhecimento acelerado, por exemplo.

O teste de primeira contagem, com resultado superior na amostra de Santa Maria, RS, pode fornecer uma ideia inicial de maior vigor, já que para Nakagawa (1999) esse teste se baseia no princípio de que amostras com maiores porcentagens de plântulas normais, na primeira contagem, são as mais vigorosas. Cherobini et al. (2008), observando a germinação de sementes de cedro, encontraram resultados de 36,79 e $89 \%$ para procedências dos estados do PR, SC e RS, respectivamente. Resultados esses próximos aos encontrados neste estudo. O vigor, ou a viabilidade, das sementes pode ser influenciado pelas condições ambientais do local de coleta. Fonseca e Freire (2003) citaram, por exemplo, a ocorrência de precipitações pluviais intensas, que podem acentuar significativamente os danos à qualidade, o que acarretará em diferenças entre procedências, como verificado neste estudo.

O teste de germinação é realizado em condições favoráveis e ótimas para a espécie, largamente utilizado para avaliação da qualidade fisiológica de sementes; todavia, pode não refletir o comportamento dessa espécie no campo, assim como não detectar estágios avançados de deterioração (FRANÇA NETTO et al., 1986), por isso a necessidade da realização de outros testes de vigor e testes a campo.

Tendo em vista que o teste de envelhecimento acelerado é uma das opções disponíveis entre os testes de vigor, mas não há informações suficientes sobre sua eficiência para sementes florestais, outros autores também os aplicaram a diferentes espécies florestais, como: Guedes et al. (2009b), com sementes de Erythrina velutina, em que as combinações de temperatura de $41^{\circ} \mathrm{C}$ por $72 \mathrm{~h} \mathrm{e} 45^{\circ} \mathrm{C}$ por $24 \mathrm{~h}$ foram adequadas para avaliação do vigor de sementes dessa espécie; e Fanti e Perez (2005), com sementes de Chorisia speciosa (Ceiba speciosa), em que o período de $72 \mathrm{~h}$ sob envelhecimento acelerado a $45{ }^{\circ} \mathrm{C}$ foi suficiente para diferenciar lotes de maior e menor vigor. Cherobini et al. (2008) encontraram resultados semelhantes ao deste estudo no teste de envelhecimento acelerado, em que o período de $48 \mathrm{~h}$ também foi eficiente para estratificar três lotes de sementes de cedro, de diferentes procedências, portanto esse período pode ser o recomendado para a realização do teste em sementes de cedro.

Para Nakagawa (1999), os testes baseados no desempenho de plântulas podem ser realizados em laboratório, em condições controladas ou em condições de campo. Esse autor relatou que a uniformidade e a rapidez de emergência de plântulas são importantes componentes dentro do conceito atual de vigor de sementes. Cherobini et al. (2008) verificaram que alguns parâmetros observados em casa de vegetação, como emergência de plântulas, altura total de mudas, comprimento das raízes, diâmetro do colo, massa verde e massa seca, conseguiram diferenciar lotes de sementes de cedro, assim como neste estudo. Sementes mais vigorosas proporcionam maior transferência de matéria seca de seus tecidos de reserva para o eixo embrionário, na fase da germinação, originando mudas com maior peso (NAKAGAWA, 1999), medido através da massa fresca e seca.

O tratamento físico e o tratamento com extrato de alho foram os que apresentaram resultados mais promissores no tratamento de sementes de cedro. $\mathrm{O}$ controle físico de sementes pode ser aplicado em vários agentes, em que os principais são a temperatura, a radiação, a ventilação e a luz (GHINI e BETIOL, 1995). A termoterapia é a forma mais conhecida de controle de patógenos em sementes e visa eliminar esses organismos, através da exposição das sementes a temperaturas elevadas sob alta (calor úmido) ou baixa umidade (calor seco).

Lazarotto et al. (2009a) verificaram que exposições de sementes de cedro ao calor seco $\left(70^{\circ} \mathrm{C}\right)$ por períodos superiores a $48 \mathrm{~h}$ diminuem, consideravelmente, a germinação da espécie, além do que tratamentos sob 
essa temperatura, a partir de $24 \mathrm{~h}$, são suficientes para erradicar fungos como Ascochyta spp. e Rhizoctonia spp. Muniz (2001) verificou que tratamentos de sementes via calor seco a $70{ }^{\circ} \mathrm{C}$, por períodos entre 8 e 15 dias, conseguiram erradicar os patógenos associados a sementes de tomate (Lycopersicum esculentum) sem prejudicar a germinação, sendo mais eficientes do que o tratamento químico utilizado.

O efeito dos extratos vegetais depende, muitas vezes, das substâncias presentes na planta de origem, já que muitas apresentam efeitos alelopáticos capazes de inibir a germinação e crescimento de plântulas, diferentemente do que ocorreu com o extrato de alho neste estudo. Schwan-Estrada et al. (2000) afirmaram que a exploração biológica de compostos secundários, presentes no extrato bruto ou óleo essencial de plantas medicinais, podem constituir, ao lado da indução da resistência, em mais uma forma potencial de controle alternativo de doenças em plantas cultivadas.

Ribeiro e Bedendo (1999) verificaram a ação "in vitro" de extratos de alho (Allium sativum), hortelã (Mentha piperita), mamona (Ricinus communis) e pimenta (Capsicum spp.) sobre o crescimento micelial e a produção de esporos de C. gloeosporioides, constatando que todos tiveram ação inibitória. Souza et al. (2007), testando o efeito dos extratos de alho e capim-santo (Cymbopogon citratus) sobre o desenvolvimento de Fusarium proliferatum isolado de grãos de milho, constataram que os extratos empregados reduziram a incidência do fungo. Além do efeito sobre o patógeno, esses autores verificaram aumento na germinação das sementes e também diminuição na incidência de tombamento e da podridão do colmo das plântulas de milho.

Extratos retirados de outras plantas também já foram testados em sementes de cedro, como fizeram Mieth et al. (2007), nas quais testaram o efeito do extrato em pó e destilado de folhas de hortelã (Mentha piperita), constatando que o extrato destilado erradicou Rhizoctonia spp. nas três concentrações testadas e o extrato em pó, nas concentrações de 30 e $20 \%$, erradicou Aspergillus spp. e Verticillium spp., respectivamente.

Esses trabalhos evidenciaram que os extratos podem ter ações específicas sobre determinados patógenos e que outras plantas, com propriedades antifúngicas em potencial, podem ser pesquisadas.
Dessa forma, verificou-se que todos os testes de avaliação de qualidade fisiológica de sementes e avaliação de mudas utilizados neste estudo foram eficientes para diferenciar as procedências de sementes de cedro em níveis de vigor; e os tratamentos com calor seco e extrato de alho foram eficientes no controle de microrganismos em sementes de cedro, sem prejuízos para seu vigor.

\section{AGRADECIMENTOS}

À Coordenação de Aperfeiçoamento de Pessoal de Nível Superior (CAPES), pela concessão da bolsa de mestrado; e à Embrapa Florestas Colombo, PR, pelo fornecimento das sementes de cedro.

\section{REFERÊNCIAS}

BRASIL. Ministério da Agricultura, Pecuária e Abastecimento. Regras para Análise de Sementes. Brasília: 2009. 399p.

CHEROBINI, E. A. I.; MUNIZ, M. F. B.; BLUME, E. Avaliação da qualidade de sementes e mudas de cedro. Ciência Florestal, v. 18, n.1, p.65-73, 2008.

FANTI, S. C.; PEREZ, S. C. J. G. A. Efeitos do envelhecimento precoce no vigor de sementes de Chorisia speciosa St. Hil. - Bombacaceae. Revista Árvore, v.29, n.3, p.345-352, 2005.

FRANÇA NETTO, J. B.; PEREIRA, L. A. G.; COSTA, N. P. Metodologia do teste de tetrazólio em sementes de soja. Londrina: Embrapa, 1986. 35p.

FREIRE, S. C. L.; FONSECA, H. B. Sementes recalcitrantes: problemas na pós-colheita. Bragantia, v.62, n.2, p.297-303, 2003.

GUEDES, R. S. et al. Tratamentos prégerminativos em sementes de Myracrodruon urundeuva Freire Allemão. Revista Árvore, v.33, n.6, p.997-1003, 2009a.

GUEDES, R. S. et al. Resposta fisiológica de sementes de Erythrina velutina Willd. Ao envelhecimento acelerado. Semina: Ciências Agrárias, v.30, n.2, p.323-330, 2009b.

Revista Árvore, Viçosa-MG, v.37, n.2, p.201-210, 2013 
GHINI, R.; BETTIOL, W. Controle físico. In: BERGAMIN FILHO, A.; KIMATI, H.; AMORIN, L. (Ed.). Manual de fitopatologia: princípios e conceitos. 3.ed. São Paulo: Agronômica Ceres, 1995. v.2. p.786-800.

LAZAROTTO, M. Qualidade fisiológica e sanitária de sementes de cedro e patogenicidade de Rhizoctonia sp. 2010. 90f. Dissertação (Mestrado em Engenharia Florestal) - Universidade Federal de Santa Maria, Santa Maria, 2010.

LAZAROTTO, M. et al. Termoterapia via calor seco no tratamento de sementes de Cedrela fissilis Vell - Meliaceae. Revista Brasileira de Agroecologia, v.4, n.2, p.730-733, 2009.

LORENZI, H. Árvores brasileiras: manual de identificação e cultivo de plantas arbóreas nativas do Brasil. Nova Odessa: Plantarum, 1992. 155p.

MARCOS FILHO, J. Testes de vigor: importância e utilização. In: KRZYZANOWSKI, F.. et al. Vigor de sementes: conceitos e testes. Londrina: ABRATES, 1999. p.1-20.

MARTINS, L.; LAGO, A. A. Conservação de semente de Cedrela fissilis: teor de água da semente e temperatura do ambiente. Revista Brasileira de Sementes, v.30, n.1, p.161-167, 2008.

MIETH, A. T. Microflora e qualidade fisiológica de sementes de cedro (Cedrella fissilis) tratadas com extrato natural de hortelã (Mentha piperita). In: CONGRESSO BRASILEIRO DE AGROECOLOGIA, 5., 2007, Guarapari. Anais... Guarapari: ABA, 2007.
MUNIZ, M. F. B. Controle de microrganismos associados a sementes de tomate através do uso do calor seco. Revista Brasileira de Sementes, v.23, n.1, p.276-280, 2001.

NAKAGAWA, J. Testes de vigor baseados no desempenho das plântulas. In: KRZYZANOWSKI, F. C. et al. (Ed.). Vigor de sementes: conceitos e testes. Londrina: ABRATES, 1999. p.1-20.

RIBEIRO, L. F.; BEDENDO, I. P. Efeito inibitório de extratos vegetais sobre Colletotrichum gloeosporioides - agente causal da podridão de frutos de mamoeiro. Scientia Agricola, v.56, n.4, p.1267-1271, 1999.

RUIZ FILHO, R. R. et al. Fungos associados às sementes de cedro. Summa

Phytopathologica, v.30, n.4, p.494-496, 2004.

SCHAWAN-ESTRADA, K. R. F.; STANGARLIN, J. R.; CRUZ, M. E. S. Uso de extratos vegetais no controle de fungos fitopatogênicos. Floresta, v.30, n.1/2, p.129-137, 2000.

SOUZA, A. E. F.; ARAÚJO, E.; NASCIMENTO, L. C. Atividade antifúngica de extratos de alho e capim-santo sobre o desenvolvimento de Fusarium proliferatum isolado de grãos de milho. Fitopatologia Brasileira, v.32, n.6, p.465-471, 2007.

WIELEWICKI, A. P. et al. Proposta de padrões de germinação e teor de água para sementes de algumas espécies florestais presentes na região sul do Brasil. Revista Brasileira de Sementes, v.28, n.3, p.191-197, 2006. 